\title{
Binding Characteristics of Radiofluorinated 6-Dialkylamino-2- Naphthylethylidene Derivatives as Positron Emission Tomography Imaging Probes for $\beta$-Amyloid Plaques in Alzheimer's Disease
}

\author{
Eric D. Agdeppa, ${ }^{1}$ Vladimir Kepe, ${ }^{1}$ Jie Liu, ${ }^{1}$ Samuel Flores-Torres, ${ }^{3}$ Nagichettiar Satyamurthy, ${ }^{1}$ Andrej Petric, ${ }^{4}$ \\ Greg M. Cole, ${ }^{5}$ Gary W. Small,, ${ }^{2}$ Sung-Cheng Huang, ${ }^{1}$ and Jorge R. Barrio ${ }^{1}$ \\ ${ }^{1}$ Division of Nuclear Medicine, Department of Molecular and Medical Pharmacology, Laboratory of Structural Biology and \\ Molecular Medicine, and ${ }^{2}$ Department of Psychiatry and Biobehavioral Sciences, University of California Los Angeles \\ School of Medicine, Los Angeles, California 90095, 3University of Puerto Rico, Cayey, Puerto Rico 00736, ${ }^{4}$ Faculty of \\ Chemistry and Chemical Technology, University of Ljubljana, SI-1000 Ljubljana, Slovenia, and 5 Veterans Administration \\ Hospital, Sepulveda, California 91343
}

Senile plaques (SPS) and neurofibrillary tangles (NFTs) are hallmark pathologies accompanying the neurodegeneration involved in Alzheimer's disease (AD), for which $\beta$-amyloid $(A \beta)$ peptide is a major constituent of SPs. Our laboratories previously developed the hydrophobic, fluorescent molecular-imaging probe 2-(1-\{6[(2-[ $\left.{ }^{18} \mathrm{~F}\right]$ fluoroethyl)(methyl)amino]-2-naphthyl\}ethylidene) malononitrile ( $\left.\left[{ }^{18} \mathrm{~F}\right] \mathrm{FDDNP}\right)$, which crosses the blood-brain barrier and determines the localization and load of SPs and NFTs in vivo in AD patients. In this report, we used fluorimetric and radioactive binding assays to determine the binding affinities of FDDNP and its analog, $1-\left\{6-\left[\left(2-\left[{ }^{18} \mathrm{~F}\right]\right.\right.\right.$ fluoroethyl) (methyl)amino]naphthalen-2-yl\}ethanone ( $\left.\left[{ }^{18} \mathrm{~F}\right] \mathrm{FENE}\right)$, to synthetic fibrils of $A \beta(1-40)$. FDDNP and FENE both appeared to bind to two kinetically distinguishable binding sites on $A \beta(1-$ 40) fibrils. Fluorescence titrations yielded apparent $K_{\mathrm{d}}$ values of 0.12 and $0.16 \mathrm{~nm}$ for high-affinity binding sites for FDDNP and
FENE, respectively, and apparent $K_{\mathrm{d}}$ values of 1.86 and $71.2 \mathrm{~nm}$ for the low-affinity binding sites. The traditional radioactive binding assays also produced apparent $K_{\mathrm{d}}$ values in the low nanomolar range. The presence of two kinetically distinguishable binding sites for FDDNP and FENE suggests multiple binding sites for SPs and identifies the parameters that allow for the structural optimization of this family of probes for in vivo use. The high-affinity binding of the probes to multiple binding sites on fibrils are consistent with results obtained with digital autoradiography, immunohistochemistry, and confocal fluorescence microscopy using human brain specimens of $A D$ patients.

Key words: $\beta$-amyloid fibrils; molecular-imaging probes; Alzheimer's disease; fluorescence titration; confocal fluorescence microscopy; digital autoradiography
Alzheimer's disease (AD) is characterized by a progressive loss of cognitive function with $\beta$-amyloid $(\mathrm{A} \beta)$ senile plaques (SPs) and neurofibrillary tangles (NFTs) as the pathological hallmarks of the disease (Vickers et al., 2000). Postmortem neuropathological examinations of the number of SPs and NFTs in the brain provide a definitive diagnosis of the disease (Ball et al., 1997). However, clinical diagnosis of AD has moderate reliability, and probable and possible AD currently lack sensitivity and specificity, respectively (Knopman et al., 2001). Early diagnosis of AD requires improvement to maximize the efficacy of potential therapies early in the disease progression and to improve the efficiency of clinical trials of therapeutic drugs. The first step toward

\footnotetext{
Received June 11, 2001; revised Aug. 31, 2001; accepted Sept. 21, 2001.

This work was supported in part by Department of Energy (DOE) Grant DE-FC0387-ER60615. E.D.A. received a Glenn/American Federation for Aging Research Scholarship for Research in the Biology of Aging. Tissue for this study was obtained from the Department of Pathology and Laboratory Medicine, University of California Los Angeles (UCLA) School of Medicine, and from the Alzheimer's Disease Center Neuropathology Core, University of Southern California Keck School of Medicine (Los Angeles, CA), which is funded by Grant P59-AG05142 from the National Institute of Aging. We thank B. Amarasekera (cyclotron), S. Gambhir and his staff (autoradiography), F. Yang, H. V. Vinters, C. A. Miller, R. Lee, Z. Kiziloglu, R. E. Keen, and the UCLA-DOE Instrumentation Laboratory.

Correspondence should be addressed to Dr. Jorge R. Barrio, Department of Molecular and Medical Pharmacology, University of California Los Angeles School of Medicine, Box 956948, Los Angeles, CA 90095-6948. E-mail: jbarrio@ mednet.ucla.edu.

Copyright (ㄷ) 2001 Society for Neuroscience $\quad 0270-6474 / 01 / 210001-05 \$ 15.00 / 0$
}

early in vivo diagnosis of $\mathrm{AD}$ is the development of molecularimaging probes to target SPs and NFTs as markers for AD.

The radiofluorinated molecular-imaging probe $2-\left(1-\left\{6-\left[\left(2-\left[{ }^{18} \mathrm{~F}\right]\right.\right.\right.\right.$ fluoroethyl)(methyl)amino]-2-naphthyl $\}$ ethylidene)malononitrile $\left(\left[{ }^{18} \mathrm{~F}\right]\right.$ FDDNP) (Scheme 1, 1), which is an analog of the highly hydrophobic, viscosity-sensitive, solvent-sensitive, fluorescent probe 2-\{1-[6-(dimethylamino)-2-naphthyl]ethylidene $\}$ malononitrile (DDNP) (Jacobson et al., 1996), has been used previously to label SPs and NFTs in the living brains of AD patients with positron emission tomography (PET) (Barrio et al., 1999). In addition to several other small molecules that label SPs and NFTs in vitro (Klunk et al., 1995; Dezutter et al., 1999; Skovronsky et

This article is published in The Journal of Neuroscience, Rapid Communications Section, which publishes brief, peerreviewed papers online, not in print. Rapid Communications are posted online approximately one month earlier than they would appear if printed. They are listed in the Table of Contents of the next open issue of JNeurosci. Cite this article as: JNeurosci, 2001, 21:RC189 (1-5). The publication date is the date of posting online at www.jneurosci.org.

http://www.jneurosci.org/cgi/content/full/5902 


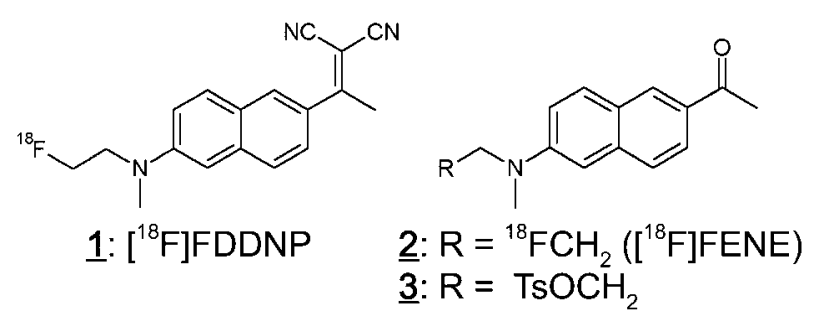

al., 2000; Styren et al., 2000), affinity for SPs and NFTs has been observed in derivatives that are structurally related to DDNP (Agdeppa et al., 2000), including the fluorescent analog $1-\left\{6\left[\left(2-\left[{ }^{18} \mathrm{~F}\right]\right.\right.\right.$ fluoroethyl)(methyl)amino]naphthalen-2-yl\}ethanone $\left(\left[{ }^{18} \mathrm{~F}\right] \mathrm{FENE}\right)$ (Scheme 1, 2).

Major constituents of SPs are aggregates of $A \beta(1-40)$ peptide (Selkoe, 1994; Teplow, 1998). Fibrils of synthetic A $\beta(1-40)$ formed in vitro resemble in vivo fibrils structurally (Miyakawa et al., 1986; Kirschner et al., 1987) and in terms of neurotoxic properties (Howlett et al., 1995; Seilheimer et al., 1997). In this work, we determined the binding constants of FDDNP and FENE to synthetic $A \beta(1-40)$ fibrils by fluorescence titration of nonradioactive FDDNP and FENE. Confocal fluorescence microscopy and immunohistochemistry were used to correlate the distribution of radiofluorinated FDDNP and FENE in digital autoradiograms of $\mathrm{AD}$ brain specimens.

\section{MATERIALS AND METHODS}

Chemicals. For fluorescence titrations, FDDNP and FENE were purified using preparative HPLC and were $99.9 \%$ pure. Solvents of spectroscopic grade or better were obtained from Fisher (Tustin, CA).

Synthesis of $\left[{ }^{18} F\right] F D D N P$ and $\left[{ }^{18} F\right] F E N E$. $\left[{ }^{18} \mathrm{~F}\right] \mathrm{FENE}$ (Scheme 1, 2) was synthesized by the modified procedure used for the preparation of $\left[{ }^{18}\right.$ F]FDDNP (Scheme 1, 1) (Barrio et al., 1999). In brief, the Bucherer reaction of 1-(6-hydroxy-2-naphthyl)ethanone with 2-methylaminoethanol yielded 1-\{6-[(2-hydroxyethyl) (methyl)amino]-2-naphthyl $\}-1-$ ethanone, which during reaction with $p$-toluenesulfonic anhydride resulted in the tosylate (Scheme 1,3). Nucleophilic substitution of the tosyl group in compound 3 by no-carrier-added $\left[{ }^{18} \mathrm{~F}\right]$ potassium fluoride/ Kryptofix 222 (Merck, Whitehouse Station, NJ) in acetonitrile yielded 2 after isolation by semipreparative HPLC (Whatman Magnum 9 silica column; Fisher) $(50 \times 1 \mathrm{~cm}$; dichloromethane; flow rate of $9 \mathrm{ml} / \mathrm{min})$ with a $20-25 \%$ radiochemical yield [corrected to end-of-synthesis (EOS)] and high specific activity $(2000-6000 \mathrm{Ci} / \mathrm{mmol}$ at EOS) in a synthesis time of $<2 \mathrm{hr}$.

Octanol-aqueous partition determination. The $\log P$ (partition) coefficients were measured according to a previously reported procedure (Unger et al., 1978). Briefly, known $\log P$ coefficients of standards were correlated to their log relative retention times with HPLC in a mobile phase of 1-octanol-saturated buffer. The $\log P$ thus determined matched the $\log P$ values calculated by $\mathrm{ACD} / \log \mathrm{P}$ software $(\mathrm{ACD} / \mathrm{I}-\mathrm{Lab}$ Service, Toronto, Ontario, Canada).

Confocal fluorescence microscopy. Freshly prepared 5 mM FDDNP and FENE solutions of ethanol were diluted to $10 \mu \mathrm{M}$ in aqueous $1 \%$ ethanol (v/v). The $10 \mu \mathrm{M}$ probe solutions were used to stain fresh, $8-\mu \mathrm{m}$-thick, neuropathologically diagnosed human AD brain specimens for $20 \mathrm{~min}$ in the absence of light. The stained tissue was quickly rinsed with distilled deionized water, followed by differentiation in a series of ethanol rinses $(70 \%, 90 \%$, and $70 \%)$ (Bancroft and Stevens, 1990), and was finally rinsed with water. Stained cryosections were mounted with Vectashield (Vector Laboratories, Burlingame, CA) on glass slides for viewing on a two photon laser-scanning Leica TCS SP MP inverted confocal microscope (Leica Microsystems, Bannockburn, IL) using 4',6-diamidino-2phenylindole (DAPI) and FITC filter sets to observe the fluorescence under the microscope. In addition, a two photon laser was also used at the appropriate excitation wavelength to digitally observe and capture images. Confocal fluorescence images were pseudocolored yellow.
Lipofuscin autofluorescence in some brain specimens was quenched before staining using $10 \mathrm{mM} \mathrm{CuCl}_{2}$ in $50 \mathrm{~mm}$ ammonium acetate buffer, pH 5 (Schnell et al., 1999). The quenching determined the origin of lipof uscin fluorescence in brain specimens.

$A \beta(1-40)$ fibril formation. A $\beta(1-40)$ (Biosource, Camarillo, CA) fibrils were prepared according to methods published previously (Klunk et al., 1999). Briefly, $0.5 \mathrm{mg}$ of $\mathrm{A} \beta(1-40)$ was dissolved in $1 \mathrm{ml}$ of PBS (Sigma, St. Louis, MO), pH 7.4, and mixed with a magnetic stir bar for $3 \mathrm{~d}$ at $37^{\circ} \mathrm{C}$, resulting in a visibly cloudy solution. The production of $\mathrm{A} \beta$ fibrils was confirmed by imaging with a Jeol 100CX transmission electron microscope (Jeol, Peabody, MA). Additional tests for fibril formation using Congo Red (Klunk et al., 1999) and Thioflavine T (LeVine, 1993) were also performed. Fibrils were used immediately after their production was confirmed.

Fluorescence titration assays. Fresh solutions of $5 \mathrm{~mm}$ FDDNP and FENE in ethanol were appropriately diluted with PBS, $\mathrm{pH} 7.4$, to obtain a final concentration range of $0.05-90 \mathrm{nM}$ probe in $4 \mathrm{ml}$ of PBS, $\mathrm{pH} 7.4$ $(0.25 \%$ ethanol), with $40 \mu \mathrm{g}$ of $\mathrm{A} \beta(1-40)$ fibrils. Fibrils were vortexed with either probe for $30 \mathrm{sec}$ followed by a $15 \mathrm{~min}$ incubation before measuring the fluorescence in Spectrocell Far UV quartz cells (Spectrocell, Oreland, PA). Excitation and fluorescence emission spectra of FDDNP and FENE were measured on a Spex Fluorolog (Jobin Yvon Horiba, Edison, NJ) with $2 \mathrm{~mm}$ excitation and emission monochromator slit-widths and a $6 \mathrm{~mm}$ photomultiplier tube slit-width. Fluorescence titrations at $20^{\circ} \mathrm{C}$ with either probe and $\mathrm{A} \beta(1-40)$ were performed with an excitation wavelength of $371 \mathrm{~nm}$ and a $400-600 \mathrm{~nm}$ scan range for emission wavelengths. All fluorescence titrations were performed in triplicate.

Equilibrium dissociation constants were graphically represented by Scatchard plots. The interactions between a macromolecule with $x$ number of different but independent binding sites for the same small molecule, such as a probe, have been generally correlated quantitatively to the following equation:

$$
r=\sum_{i=1}^{x} \frac{n_{x}[\text { Free probe }]}{K_{\mathrm{d}, x}+[\text { Free probe }]}
$$

where $r$ is the moles of bound probe per moles of total $\mathrm{A} \beta(1-40)$ peptide, $n_{x}$ is the number of binding sites of class $x, K_{\mathrm{d}}$ is the equilibrium dissociation constant, and [Free probe] is the molar concentration of nonbound probe (Freifelder, 1982) (Fig. 1C,D). The concentration of the free probe was calculated with a modified equation used by Yang et al. (1999):

$$
[\text { Free probe }]=[\text { Total probe }]\left(P-\frac{I}{I_{0}}\right) /(P-1),
$$

where [Free probe] and [Total probe] are the concentration of the free probe and the total concentration of the probe added, respectively. $I_{0}$ and $I$ represent the observed fluorescence intensities in the absence and presence of fibrils at the same total concentration of probe, respectively. $P$ corresponds to the ratio of quantum yields for one molecule of bound probe to one molecule of free probe, as determined by the asymptotic value of $I$ in a plot of $1 / I$ versus $1 /[$ Total probe $]$.

Radioactive binding assay to $A \beta(1-40)$ fibrils. Fresh, nonradioactive 5 mM FDDNP and FENE solutions in ethanol were prepared for each radioactive assay. A $0.05-90 \mathrm{~nm}$ range of each probe was made by adding an appropriate amount of nonradioactive probe to the radiolabeled derivative in PBS, $\mathrm{pH} 7.4$, to achieve a final ethanol concentration of $0.25 \%$ when the fibrils were added. Forty microgram $\mathrm{A} \beta(1-40)$ fibrils were vortexed and subsequently incubated in a test tube with an aliquot of probe from the range of concentrations above for $15 \mathrm{~min}$ before vacuum filtration using type APFF glass fiber filters $(0.7 \mu \mathrm{m}$ particle retention; Millipore, Bedford, MA) in a 1225 sampling manifold (Millipore) modified with stainless steel support screens (Millipore) and glass sample chambers. Each filter was then washed twice with $3 \mathrm{ml}$ of PBS, $\mathrm{pH}$ 7.4 , to minimize nonspecific binding of the probes. All radioactive binding assays were performed in triplicate.

AD brain tissue for digital autoradiography. Postmortem-diagnosed definite AD brain tissue and normal control brain tissue were obtained from two males with time to autopsy of $<4 \mathrm{hr}$. All brain specimens were immediately treated with $10 \%$ buffered formalin phosphate (Fisher) for 


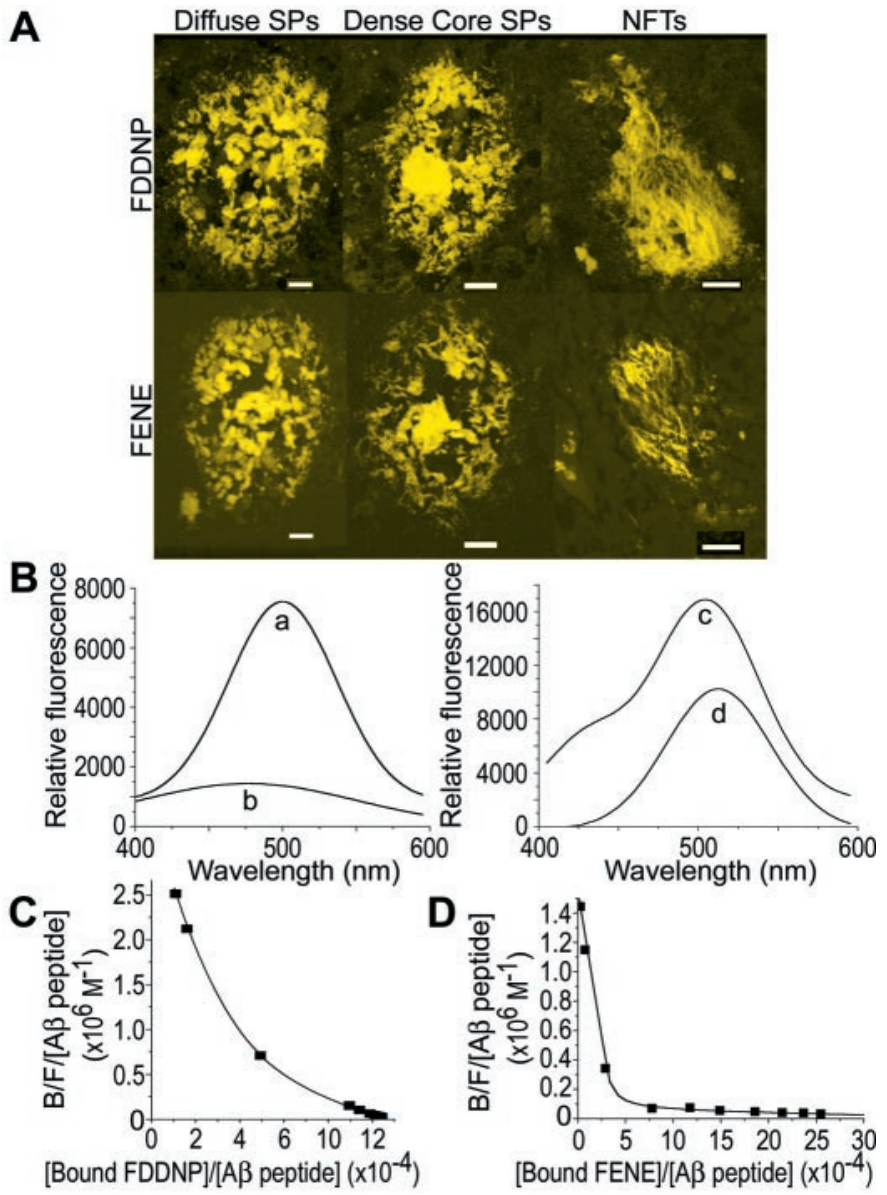

Figure 1. Fluorescence enhancement observed when probes were bound to lesions and in vitro fibrils. $A$, Confocal fluorescence images of human AD brain specimens showing diffuse SPs, dense core SPs, and NFTs labeled with FDDNP (top row) and FENE (bottom row). All images were pseudocolored yellow. Scale bar, $10 \mu \mathrm{m}$. B, Enhancement of probe fluorescence and resultant binding data with $\mathrm{A} \beta(1-40)$ fibrils. Solventcorrected emission spectra of the following: $a, 1.2 \mathrm{~nm}$ FDDNP in PBS, $\mathrm{pH}$ 7.4, added to $10 \mu \mathrm{g} / \mathrm{ml} \mathrm{A} \beta(1-40)$ fibrils; $b, 1.2 \mathrm{~nm}$ FDDNP in PBS, $\mathrm{pH}$ 7.4; $c, 1.2$ nM FENE in PBS, $\mathrm{pH} 7.4$, added to $10 \mu \mathrm{g} / \mathrm{ml} \mathrm{A} \beta(1-40)$ fibrils; and $d, 1.2 \mathrm{nM}$ FENE in PBS, pH 7.4. $C, D$, Scatchard plots of FDDNP and FENE binding to $10 \mu \mathrm{g} / \mathrm{ml} \mathrm{A} \beta(1-40)$ fibrils, as determined by fluorescence titrations; $B / F /[A \beta$ peptide $]$ is the ratio of moles of bound probe to moles of free probe per molar $\mathrm{A} \beta(1-40)$ peptide; [Bound FDDNP] and [Bound FENE] are the molar concentrations of bound FDDNP and FENE, respectively. Fluorescence titrations were performed in triplicate.

several weeks depending on tissue size. The formalin-treated specimens were subsequently cryoprotected with $20 \%$ aqueous sucrose solution for at least 1 month, with the solution being changed every 2 weeks. The cryoprotected $\mathrm{AD}$ tissue was subsequently stored at $-80^{\circ} \mathrm{C}$ before cryosectioning. Cryosections of $100 \mu \mathrm{m}$ thickness from AD and control brains were used for autoradiography and immunostaining. All cryosections were mounted on gelatin-coated glass slides, allowed to air dry, and stored at $-80^{\circ} \mathrm{C}$. At 1 day before use with autoradiography, cryosections were thawed, defatted for $40 \mathrm{~min}$ in xylene (Loopuijt et al., 1987), and then washed with ethanol.

Digital autoradiography. $\mathrm{AD}$ and control cryosections were incubated for $25 \mathrm{~min}$ at room temperature with $3.7 \mathrm{MBq}$ of $\left[{ }^{18} \mathrm{~F}\right] \mathrm{FDDNP}$ or $\left[{ }^{18} \mathrm{~F}\right] \mathrm{FENE}$ dissolved in $10 \mathrm{ml}$ of $1 \%$ ethanol in $0.9 \%$ saline $(\mathrm{w} / \mathrm{v})$ per cryosection. After incubation, the sections were optimally washed with water $(30 \mathrm{sec})$, with $70 \%-90 \%-70 \%$ ethanol (1 min each) for $\left[{ }^{18} \mathrm{~F}\right]$ FDDNP or pure ethanol $(15 \mathrm{~min})$ for $\left[{ }^{18} \mathrm{~F}\right] \mathrm{FENE}$ for differentiation (Bancroft and Stevens, 1990), and then with water again $(30 \mathrm{sec})$. The tissues were dried on a warm hot plate with a steady stream of cold dry air and exposed to $\beta^{+}$-sensitive phosphor plates. Digital autoradiography was performed using a Fuji BAS 5000 phosphorimager (Fuji, Tokyo, Japan) and phosphor plates with a resolution of $\sim 100 \mu \mathrm{m}$, as described previously (Gambhir et al., 1998).

Immunohistochemistry. Cryosections from the same region of the brain were labeled with tau (AT8, serine 202 phosphotau; Innogenetiks, Ghent, Belgium) and $\mathrm{A} \beta(10 \mathrm{G} 4, \mathrm{~A} \beta(1-15))$ (Yang et al., 1994) antibodies. The $100-\mu \mathrm{m}$-thick cryosections were incubated with AT8 and 10G4 at 1:800, and the immunostaining was developed with a Vectastain Elite avidinbiotin complex kit (Vector Laboratories) using peroxidase and diaminobenzidine (DAB) detection.

\section{RESULTS}

\section{Binding specificity for SPs and NFTs as demonstrated by confocal fluorescence microscopy}

AD brain specimens, which were stained with FDDNP and FENE, revealed not only an intense labeling of dense core and diffuse plaques but also a fainter labeling of NFTs (Fig. 1A). Minimal background staining was observed in either white or gray matter, and no other pathology was appreciably labeled. Lipof uscin fluorescence, which was observed in all stained tissue, was shown to be attributable to lipof uscin autofluorescence and not to probe labeling. Observations of tissue with no probe staining showed lipofuscin autofluorescence. Tissue stained with either probe had an absence of lipofuscin fluorescence when lipof uscin autofluorescence was quenched with $\mathrm{CuCl}_{2}$ (Schnell et al., 1999).

\section{Fluorescence titrations reveal two classes of binding sites to $A \beta$ fibrils}

An enhanced fluorescence emission was observed when the $\mathrm{A} \beta(1-40)$ fibrils were titrated with FDDNP and FENE compared with titrations without fibrils in PBS (Fig. $1 B$ ). The spectral change, which was unique to the presence of fibrils, allowed for the distinction of two kinetically distinguishable binding sites in $\mathrm{A} \beta(1-40)$ fibrils (Fig. $1 C, D)$. The high-affinity binding sites of the A $\beta(1-40)$ fibrils for FDDNP and FENE yielded apparent $K_{\mathrm{d}}$ values of 0.12 and $0.16 \mathrm{~nm}$, respectively (Table 1 ). The apparent $K_{\mathrm{d}}$ values for the low-affinity binding sites in the $\mathrm{A} \beta(1-40)$ fibrils for FDDNP and FENE were 1.86 and $71.2 \mathrm{~nm}$, respectively (Table 1). The optimal ethanol concentration of the binding solution was $0.25 \%(\mathrm{v} / \mathrm{v})$. Higher concentrations of ethanol produced an underestimation of binding affinities. Radioactive binding assays also yielded somewhat lowered binding affinities compared with values from fluorescence binding determinations because of the mechanical separation of free probes from fibrilbound probes by filtration and buffer washes (Bolger et al., 1998). Moreover, efficient mechanical separations (e.g., filtration) require increased alcohol levels (e.g., $1 \%$ instead of $0.25 \%$ ), further affecting the binding determination. For example, the apparent $K_{\mathrm{d}}$ values of $\left[{ }^{18} \mathrm{~F}\right] \mathrm{FENE}$ in $1 \%$ ethanol, as opposed to $0.25 \%$, were 9.50 and $90.8 \mathrm{~nm}$ for the high- and low-affinity binding sites, respectively.

\section{Autoradiograms reveal specific binding to areas of SPs and NFTs}

Digital autoradiography of $\mathrm{AD}$ brain specimens using $\left[{ }^{18} \mathrm{~F}\right]$ FDDNP and $\left[{ }^{18} \mathrm{~F}\right] \mathrm{FENE}$ (Fig. $2 A, C$ ) revealed binding of both probes in the temporal and parietal cortices, matching the immunohistochemistry of nearby adjacent slices (Fig. 2E). Confocal fluorescence microscopy revealed that the pattern in the autoradiograms and immunostained tissue originated from SPs and NFTs. In the case of both probes, control brain tissue revealed nonspecific binding (Fig. 2B,D). 
Table 1. Binding data of FDDNP and FENE for synthetic A $\beta(1-40)$ fibrils

\begin{tabular}{|c|c|c|c|c|}
\hline \multirow[b]{2}{*}{ Binding site } & \multicolumn{2}{|l|}{ FDDNP } & \multicolumn{2}{|l|}{ FENE } \\
\hline & High & Low & High & Low \\
\hline Apparent $K_{\mathrm{d}}$ & $0.12 \pm 0.02 \mathrm{~nm}$ & $1.86 \pm 0.22 \mathrm{~nm}$ & $0.16 \pm 0.09 \mathrm{~nm}$ & $71.2 \pm 8.6 \mathrm{~nm}$ \\
\hline$B_{\max }$ & $80.8 \mathrm{pmol} / \mathrm{mg}$ & $164 \mathrm{pmol} / \mathrm{mg}$ & $64.7 \mathrm{pmol} / \mathrm{mg}$ & $982 \mathrm{pmol} / \mathrm{mg}$ \\
\hline$n$ & $3.50 / 10,000$ & $7.10 / 10,000$ & $2.80 / 10,000$ & $42.5 / 10,000$ \\
\hline
\end{tabular}

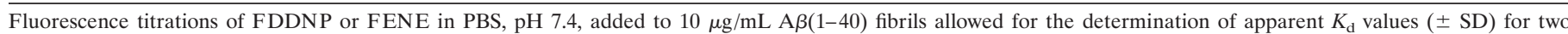

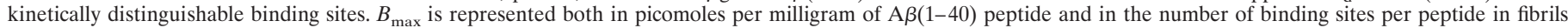
$(n)$.

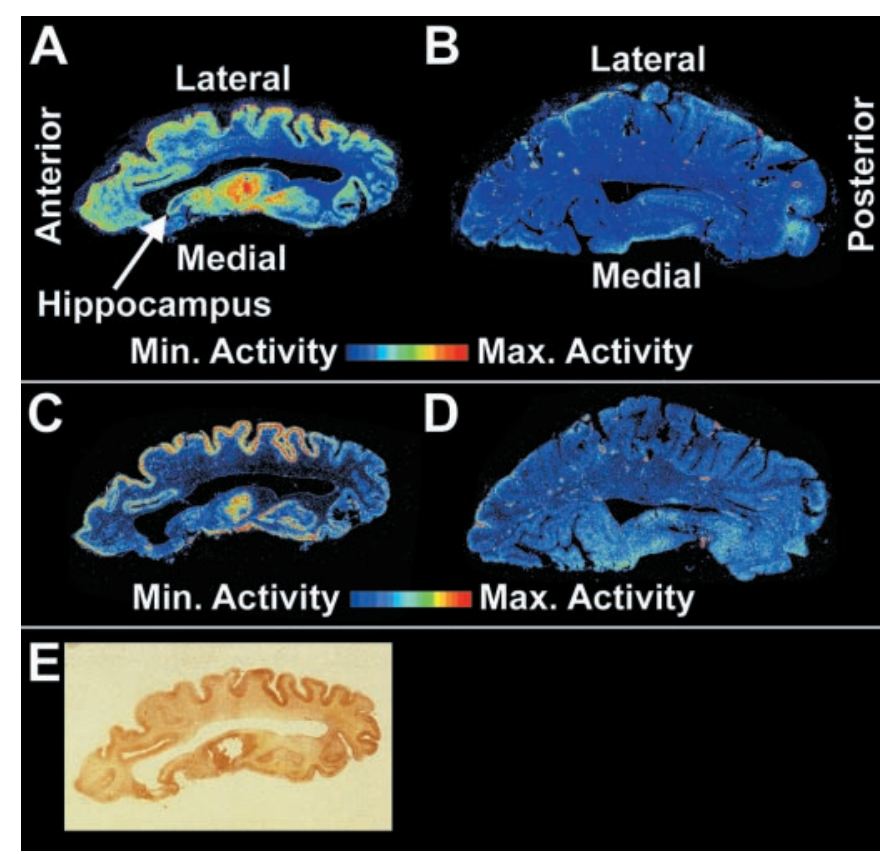

Figure 2. Autoradiograms of $\mathrm{AD}$ and control brain specimens labeled with $\left[{ }^{18} \mathrm{~F}\right] \mathrm{FDDNP}$ and $\left[{ }^{18} \mathrm{~F}\right] \mathrm{FENE}$. Color-coded digital autoradiograms labeled in vitro with $\left[{ }^{18} \mathrm{~F}\right] \mathrm{FDDNP}(A, B)$ and $\left[{ }^{18} \mathrm{~F}\right] \mathrm{FENE}(C, D)$ showing oblique, $100-\mu \mathrm{m}$-thick cryosections through the hippocampus and temporal lobe of an $\mathrm{AD}$ patient $(A, C)$ and a control subject $(B, D)$ are shown. Autoradiograms of control cryosections revealed uniform, nonspecific binding of each probe at a level similar to the nonspecific binding of each probe in the white matter of AD cryosections. $E$, A cryosection $\sim 1.4 \mathrm{~mm}$ inferior to the above autoradiograms from the same region of the brain was labeled with tau (AT8, serine, 202 phosphotau) and $\mathrm{A} \beta$ (10G4, $\mathrm{A} \beta(1-15))$ antibodies. When examined microscopically, the gross pattern of brown DAB deposition representing tau plus $\mathrm{A} \beta$ immunoreactivity stemmed entirely from authentic plaque and tau (tangles, curly fibers, and dystrophic neurites) staining.

\section{DISCUSSION}

Fluorescence binding determinations are a powerful quantitative tool to determine the binding affinity of probes to SPs (Kuner et al., 2000) and a wide variety of other macromolecules (Eftink, 1997). Besides the apparent benefit of eliminating the use of radioisotopes, another practical consideration is the use of less synthetic fibrils (e.g., $120 \mu \mathrm{g}$ of $\mathrm{A} \beta(1-40)$ /triplicate) with fluorescence titrations compared with the traditional radioactive binding assays that use $>1 \mathrm{mg}$ of peptide for triplicate results at a cost of $\sim \$ 250$ per milligram of peptide. Methodologically, the fluorescence titration does not involve the mechanical separation of free probes from fibril-bound probes by filtration and buffer washes, thus avoiding perturbations of the binding equilibrium between the probes and binding sites on the fibrils (Bolger et al., 1998).
Fluorescence enhancement was analyzed using a modified method originally developed for DNA-fluorophore interactions (Oster, 1951). Equation 2 is suitable for the analysis of FDDNP and FENE binding to $A \beta(1-40)$ fibrils because of the utility of the original equation for probe binding to heterogeneous binding sites (Blake and Peacocke, 1968). Unlike other analyses of fluorescence enhancement of protein-binding dyes, Equation 2 does not include assumptions of the maximum number of probes bound per protein nor does it exclude low-affinity binding sites in relating fluorescence enhancement with the fraction of bound probe (Athar et al., 1999; Petersen et al., 2000).

The fluorescence enhancement observed with FDDNP and FENE bound to $\mathrm{A} \beta(1-40)$ fibrils indicates probe binding to hydrophobic surface clefts. The absence of significant metachromic shifts accompanying the binding of the probes suggests that the probes bound to the fibrils are not entirely shielded from the aqueous environment (Jacobson et al., 1996). The low number of total binding sites per $\mathrm{A} \beta(1-40)$ peptide (Table 1) indicates a macromolecular conformation of fibrils that leads to probebinding sites instead of specific probe interactions with individual A $\beta(1-40)$ peptides. The structural similarity of FDDNP and FENE and similar $K_{\mathrm{d}}$ values for the high-affinity binding sites of both probes suggest that they might bind to similar sites. Additional work, specifically competitive binding assays, is necessary to determine whether the probes share the same binding sites with each other, as well as with other amyloid dyes (e.g., Congo Red, Chrysamine G, Thioflavine T).

The apparent $K_{\mathrm{d}}$ values for FDDNP and FENE in the low nanomolar range (Table 1) are consistent with the specific labeling of SPs, as is microscopically evident by the confocal fluorescence images (Fig. $1 A$ ) and the gross pattern of binding observed with the digital autoradiography and immunostaining (Fig. $2 A, C, E)$. It should be understood, however, that SPs are characteristically heterogeneous, consisting of cellular products other than $\mathrm{A} \beta$ peptides (Dickson, 1997). FDDNP and FENE binding to SPs as well as NFTs in AD brain specimens was highly specific. The fluorescence of lipofuscins, which were observed in tissue stained by both probes, was determined to be attributable to lipofuscin autofluorescence and not to labeling by either probe.

The high hydrophobicity and, in particular, the apparent $K_{\mathrm{d}}$ values in the low nanomolar range of $\left[{ }^{18} \mathrm{~F}\right] \mathrm{FDDNP}$ suggest its promising use in vivo with PET in contrast to $\left[{ }^{18} \mathrm{~F}\right] \mathrm{FENE}$. Both imaging probes are highly diffusible across the blood-brain barrier because of their high hydrophobicity (FDDNP, $\log P=3.92$; FENE, $\log P=3.13$ ). If one were to consider SP binding of these probes as the classic receptor-ligand interaction, then $\left[{ }^{18} \mathrm{~F}\right]$ FDDNP satisfies the requirement that in vivo visualization of ligand binding to brain receptors have $K_{\mathrm{d}}$ values in the nanomolar range for effective separation of specific versus nonspecific binding. 
It is anticipated that probes (e.g., $\left[{ }^{18} \mathrm{~F}\right] \mathrm{FENE}$ ) with a low-affinity binding site with higher capacity than that of the high-affinity binding site (e.g., $n$ value, Table 1) will have limitations as molecular-imaging probes with PET because the preponderance of the weakly bound probe will obscure the signal from the highaffinity binding site. Because FDDNP has low $K_{\mathrm{d}}$ values for both high- and low-affinity binding sites to $\mathrm{A} \beta$ fibrils (Table 1 ), it is not surprising that FDDNP is such a promising in vivo marker for SPs.

Indeed, the most compelling characteristic of $\left[{ }^{18} \mathrm{~F}\right] \mathrm{FDDNP}$ is its ability to label SPs and NFTs in the living human brain with PET (Barrio et al., 1999; Agdeppa et al., 2001; Shoghi-Jadid et al., 2001). The imaging data show (1) increased retention of $\left[{ }^{18} \mathrm{~F}\right]$ FDDNP in regions of brain hypometabolism and atrophy consistent with areas known to develop SPs and NFTs (Braak and Braak, 1991) and (2) quantitative results correlated with lower memory-performance scores (Shoghi-Jadid et al., 2001).

In this work, the binding characteristics of these new molecular-imaging probes to SPs will help identify parameters that allow for the structural optimization for this family of compounds (Agdeppa et al., 2000). Specifically, the presence of the dicyano group in FDDNP appears critical for high-affinity binding. Similar binding determinations of this family of probes to NFTs or synthetic tau filaments (King et al., 1999) are awaiting. The determination of the apparent $K_{\mathrm{d}}$ values for SPs of these new analogs and their ability to label SPs and NFTs, as evidenced by confocal fluorescence microscopy and autoradiography, are thus powerful predictive tools in the identification of molecularimaging probes for in vivo use with PET.

\section{REFERENCES}

Agdeppa ED, Kepe V, Kiziloglu ZN, Petric A, Zabjek A, Satyamurthy N, Cole GM, Vinters HV, Small GW, Barrio JR (2000) FDDNP analogs as probes for plaques and tangles in Alzheimer's disease. J Nucl Med 41:25P.

Agdeppa ED, Kepe V, Shoghi-Jadid K, Satyamurthy N, Small GW, Petric A, Vinters HV, Huang S-C, Barrio JR (2001) In vivo and in vitro labeling of plaques and tangles in the brain of an Alzheimer's disease patient: a case study. J Nucl Med 42:65P.

Athar H, Ahmad N, Tayyab S, Qasim MA (1999) Use of fluorescence enhancement technique to study bilirubin-albumin interaction. Int J Biol Macromol 25:353-358.

Ball M, Braak H, Coleman P, Dickson D, Duyckaerts C, Gambetti P, Hansen L, Hyman B, Jellinger K, Markesbery W, Perl D, Powers J, Price J, Trojanowski JQ, Wisniewski H, Phelps C, Khachaturian Z (1997) Consensus recommendations for the postmortem diagnosis of Alzheimer's disease. Neurobiol Aging 18:S1-S2.

Bancroft JD, Stevens A, eds (1990) Theory and practice of histological techniques, Ed 3. Edinburgh, NY: Churchill Livingstone.

Barrio JR, Huang SC, Cole G, Satyamurthy N, Petric A, Phelps ME, Small G (1999) PET imaging of tangles and plaques in Alzheimer disease with a highly hydrophobic probe. J Labelled Compd Radiopharm 42:S194-S195.

Blake A, Peacocke AR (1968) The interaction of aminoacrinidines with nucleic acids. Biopolymers 6:1225-1253.

Bolger R, Wiese TE, Ervin K, Nestich S, Checovich W (1998) Rapid screening of environmental chemicals for estrogen receptor binding capacity. Environ Health Perspect 106:551-557.

Braak H, Braak E (1991) Neuropathological staging of Alzheimerrelated changes. Acta Neuropathol (Berl) 82:239-259.

Dezutter NA, Dom RJ, de Groot TJ, Bormans GM, Verbruggen AM (1999) ${ }^{99 m}$ Tc-MAMA-chrysamine $\mathrm{G}$, a probe for $\beta$-amyloid protein of Alzheimer's disease. Eur J Nucl Med 26:1392-1399.

Dickson DW (1997) Neuropathological diagnosis of Alzheimer's disease: a perspective from longitudinal clinicopathological studies. Neurobiol Aging 18:S21-S26.

Eftink MR (1997) Fluorescence methods for studying equilibrium macromolecule-ligand interactions. Methods Enzymol 278:221-257.

Freifelder D (1982) Physical biochemistry: applications to biochemistry and molecular biology, Ed 2. San Francisco: Freeman.

Gambhir SS, Barrio JR, Wu L, Iyer M, Namavari M, Satyamurthy N, Bauer E, Parrish C, MacLaren DC, Borghei AR, Green LA, Sharfstein S, Berk AJ, Cherry SR, Phelps ME, Herschman HR (1998) Imaging of adenoviral-directed herpes simplex virus type 1 thymidine kinase reporter gene expression in mice with radiolabeled ganciclovir. J Nucl Med 39:2003-2011.

Howlett DR, Jennings KH, Lee DC, Clark MS, Brown F, Wetzel R, Wood SJ, Camilleri P, Roberts GW (1995) Aggregation state and neurotoxic properties of Alzheimer $\beta$-amyloid peptide. Neurodegeneration 4:23-32.

Jacobson A, Petric A, Hogenkamp D, Sinur A, Barrio JR (1996) 1,1dicyano-2-(6-dimethylaminonaphthalen-2-yl)propene (DDNP): a solvent polarity- and viscosity-sensitive fluorophore for fluorescence microscopy. J Am Chem Soc 118:5572-5579.

King ME, Ahuja V, Binder LI, Kuret J (1999) Ligand-dependent tau filament formation: implications for Alzheimer's disease progression. Biochemistry 38:14851-14859.

Kirschner DA, Inouye H, Duffy LK, Sinclair A, Lind M, Selkoe DJ (1987) Synthetic peptide homologous to $\beta$ protein from Alzheimer disease forms amyloid-like fibrils in vitro. Proc Natl Acad Sci USA 84:6953-6957.

Klunk WE, Debnath ML, Pettegrew JW (1995) Chrysamine-G binding to Alzheimer and control brain: autopsy study of a new amyloid probe. Neurobiol Aging 16:541-548.

Klunk WE, Jacob RF, Mason RP (1999) Quantifying amyloid $\beta$-peptide $(\mathrm{A} \beta)$ aggregation using the Congo red- $\mathrm{A} \beta(\mathrm{CR}-\mathrm{A} \beta)$ spectrophotometric assay. Anal Biochem 266:66-76.

Knopman DS, DeKosky ST, Cummings JL, Chui H, Corey-Bloom J, Relkin N, Small GW, Miller B, Stevens JC (2001) Practice parameter: diagnosis of dementia (an evidence-based review). Report of the Quality Standards Subcommittee of the American Academy of Neurology. Neurology 56:1143-1153.

Kuner P, Bohrmann B, Tjernberg LO, Näslund J, Huber G, Celenk S, Grüninger-Leitch F, Richards JG, Jakob-Roetne R, Kemp JA, Nordstedt $C$ (2000) Controlling polymerization of $\beta$-amyloid and prionderived peptides with synthetic small molecule ligands. J Biol Chem 275:1673-1678

LeVine H (1993) Thioflavine T interaction with synthetic Alzheimer's disease $\beta$-amyloid peptides: detection of amyloid aggregation in solution. Protein Sci 2:404-410.

Loopuijt LD, Sebens JB, Korf J (1987) In vivo labeling of dopamine receptors: light microscopic localization at the cellular level by means of dipping autoradiography with the agonist $\left({ }^{3} \mathrm{H}\right) \mathrm{N}-n$-propylnorapomorphine. J Neural Transm 68:15-23.

Miyakawa T, Katsuragi S, Watanabe K, Shimoji A, Ikeuchi Y (1986) Ultrastructural studies of amyloid fibrils and senile plaques in human brain. Acta Neuropathol (Berl) 70:202-208.

Oster G (1951) Fluorescence quenching by nucleic acids. Trans Faraday Soc 47:660-666.

Petersen CE, Ha CE, Harohalli K, Park DS, Bhagavan NV (2000) Familial dysalbuminemic byperthyroxinemia may result in altered warfarin pharmacokinetics. Chem Biol Interact 124:161-172.

Schnell SA, Staines WA, Wessendorf MW (1999) Reduction of lipof uscin-like autofluorescence in fluorescently labeled tissue. J Histochem Cytochem 47:719-730.

Seilheimer B, Bohrmann B, Bondolfi L, Müller F, Stüber D, Döbeli H (1997) The toxicity of the Alzheimer's $\beta$-amyloid peptide correlates with a distinct fiber morphology. J Struct Biol 119:59-71.

Selkoe DJ (1994) Cell biology of the amyloid $\beta$-protein precursor and the mechanism of Alzheimer's disease. Annu Rev Cell Biol 10:373-403

Shoghi-Jadid K, Small GW, Agdeppa ED, Kepe V, Ercoli LM, Siddarth P, Read S, Satyamurthy N, Petric A, Huang S-C, Barrio JR (2001) Localization of neurofibrillary tangles and $\beta$-amyloid plaques in the brains of living patients with Alzheimer's disease. Am J Geriatr Psychiatry, in press.

Skovronsky DM, Zhang B, Kung MP, Kung HF, Trojanowski JQ, Lee VM (2000) In vivo detection of amyloid plaques in a mouse model of Alzheimer's disease. Proc Natl Acad Sci USA 97:7609-7614.

Styren SD, Hamilton RL, Styren GC, Klunk WE (2000) X-34, a fluorescent derivative of Congo red: a novel histochemical stain for Alzheimer's disease pathology. J Histochem Cytochem 48:1223-1232.

Teplow DB (1998) Structural and kinetic features of amyloid $\beta$-protein fibrillogenesis. Amyloid 5:121-142.

Unger SH, Cook JR, Hollenberg JS (1978) Simple procedure for determining octanol-aqueous partition, distribution, and ionization coefficients by reversed-phase high-pressure liquid chromatography. J Pharm Sci 67:1364-1367.

Vickers JC, Dickson TC, Adlard PA, Saunders HL, King CE, McCormack G (2000) The cause of neuronal degeneration in Alzheimer's disease. Prog Neurobiol 60:139-165.

Yang F, Mak K, Vinters HV, Frautschy SA, Cole GM (1994) Monoclonal antibody to the $\mathrm{C}$-terminus of $\beta$-amyloid. NeuroReport 5:2117-2120.

Yang X, Liu W-H, Jin W-J, Shen G-L, Yu R-Q (1999) DNA binding studies of a solvatochromic fluorescence probe 3-methoxybenzanthrone. Spectrochim Acta A Mol Biomol Spectrosc 55:2719-2727. 